\title{
Position Statement on Breastfeeding from the Italian Pediatric Societies
}

\author{
Riccardo Davanzo ${ }^{1 *}$, Costantino Romagnoli ${ }^{2}$ and Giovanni Corsello ${ }^{3}$
}

\begin{abstract}
The 2015 Position Statement on Breastfeeding of The Italian Pediatric Societies (SIP, SIN, SICupp, SIGENP) recognizes breastfeeding as an healthy behaviour with many short and long term benefits for both mother and infant. While protecting, promoting and supporting breastfeeding, neonatologists and pediatricians need specific knowledge, skills and a positive attitude toward breastfeeding. In Maternity Hospitals and in Neonatal Units, appropriate organizative interventions should be applied in order to facilitate the beginning of breastfeeding and the use of mother's/human milk.

The Italian Pediatric Societies indicate the desiderable goal of around 6 months exclusive breastfeeding if the infant grows properly according to WHO Growth Charts. In principle, complementary feeding should not be anticipated before 6 months as a nutritional strategy pretending to prevent allergy and/or celiac disease. Eventually, long term breastfeeding should be supported meeting mother's desire.
\end{abstract}

Keywords: Breastfeeding, Human milk, Position statement

\section{Background}

Human milk is a individual-specific, biological and highly biodiverse liquid, that makes people equal in their nutrition and health opportunities. Moreover, breastfeeding, with its intimate relationship between mother and baby, is the cultural model for tolerance, variability-flexibility, and interaction between individuals and a worldwide action in terms of sustainability, environmental friendliness, and equality.

Limited data show that breastfeeding rates in Italy are suboptimal [1-4] when compared with Recommendations on Infant Feeding by WHO [5].

Given current epidemiological data on suboptimal Breastfeeding rates in Italy, health professionals, particularly pediatricians and neonatologists, have an important role in the protection, promotion and support of breastfeeding [6], both in Health Facilities and in the Comunity. Nevertheless, to effectively facilitate breastfeeding, they need specific knowledge and skills $[7,8]$ accompanied by a positive attitude toward breastfeeding [9].

\footnotetext{
* Correspondence: riccardo.davanzo@gmail.com

'Division of Neonatology, Maternal and Child Health Institute-IRCCS "Burlo Garofolo" Trieste, Via dell'Istria 65/1, 34100 Trieste, Italy

Full list of author information is available at the end of the article
}

As breastfeeding is a healthy behaviour, the Italian Pediatric Societies (Italian Society of Neonatology -SIN, Italian Society of Primary Pediatric Care -SICuPP, Italian Society of Pediatric Gastroenterology and Nutricion SIGENP) have developed a statement to witness their position and to call pediatricians and neonatologists for action.

An ad hoc Working Group of the Italian Society of Pediatrics completed the Position Statement in August 2015. During September 2015 the Task Force on Breastfeeding of the Ministry of Health, Italy and the Executive Committees of SIP, SIN, SICupp and SIGENP approved the final version.

\section{Extract of the position statement on breastfeeding}

The Position Statement on Breastfeeding (access to http://www.neonatologia.it/upload/2265_Position\%20Statement\%2013\%20sett\%202015.pdf for the full Italian text) can be resumed in the following points:

1. Breastfeeding carries well proven benefits to the health of both the mother and his/her baby $[10,11]$ and to the comunity in term of reduced costs for health care $[12,13]$ and to environmental sustainability 
2. Breastfeeding should be considered as a nutritional norm. Although natural, breastfeeding must be learned by new mothers, who may face obstacles particularly at the beginning of breastfeeding, in the Maternity Hospitals as well as after hospital discharge. Breastfeeding mothers need advice and support from skilled professionals, who should keep a positive attitude toward breatfeeding.

3. While promoting breastfeeding, the neonatologist and the pediatrician should develop a general awareness on possible conflicts of interest, particularly regarding connection with baby food industry.

4. The informed choice of a mother for formula feeding should be accepted without discrimination versus a breastfeeding mother.

5. Data on breastfeeding rates should be collected using the WHO feeding definitions, both at Maternity and NICU discharge [14] and at least at the first immunization sessions at around 3 and 5 months of age.

6. The neonatologist and the pediatrician should develop an adequate knowledge and training on the physiology of lactation and the management of breastfeeding.

7. Breastfeeding should be contraindicated only for good medical reasons [15]. Radiological contrast agents are almost always compatible [16]. The lactation risk of medicines assumed by the mother should be assessed with an evidence based methodology, that ultimately demontrates that most drugs are safe while breastfeeding (9). Environmental contaminants should not be a reason to interrupt breastfeeding, as the benefits outweigh the risks. A new pregnancy in the first two trimesters is not a contraindication to breastfeed [17].

8. In Maternity Hospitals, neonatologist and pediatrician should use clinical and organizative protocols, that combine breastfeeding promotion with the evidence based neonatological and pediatric best practice $[18,19]$

9. The Italian Pediatric Societies reccommend exclusive breastfeeding for about 6 months of life [20-22]. Poor growth properly assessed with the WHO Grow Charts [http://www.cdc.gov/ growthcharts/who_charts.htm\#The\%20WHO\%20 Growth\%20Charts] may suggest to anticipate the introduction of weaning foods between the fourth and the sixth month. Breastfeeding might continue after the introduction of semi-solids and solid foods, beyond 2 years of life according to mother 's desire [23-26].

10.Evidence based interventions proven to promote breastfeeding and the use of human milk should be applied in the NICUs [27]. Donor Milk Banks are component of this promotion [28, 29], although a cost/benefit ratio should be assessed before implementing a new one.

\section{Conclusion}

The 2015 Position Statement of the Italian Pediatric Societies may represent a scientific and ethical reference tool for a more effective committment of neonatologists and pediatricians to increase breastfeeding among Italian pediatric population.

\section{Competing interests}

The authors declare no potential conflicts of interests with respects to the content of this article.

\section{Authors' contributions}

$\mathrm{RD}$ conceived the Project of the Position Statement on Breastfeeding, coordinated the ad hoc working group and has been the main Author of the document. RD, CR and GC wrote this manuscript. All Authors approved the final version.

\section{Aknowledgment}

We recognize that the Italian version of the Position Statement on Breastfeeding of the Italian Pediatric Societis have been writted by Carlo Agostoni (Milano), Enrico Bertino (Torino), Teresa Cazzato (Taranto), Riccardo Davanzo (Trieste), Claudio Maffeis (Verona), Fabio Natale (Roma), Marco Silano (Roma), Annamarina Staiano (Napoli), Paola Tonetto (Torino), Renato Vitiello (Napoli)

\section{Author details}

'Division of Neonatology, Maternal and Child Health Institute-IRCCS "Burlo Garofolo" Trieste, Via dell'Istria 65/1, 34100 Trieste, Italy. ${ }^{2}$ Department of Pediatrics, Division of Neonatology, Catholic University S H, Rome, Italy. ${ }^{3}$ Department of Sciences for Health Promotion and Mother and Child Care, University of Palermo, Palermo, Italy.

Received: 30 September 2015 Accepted: 16 October 2015

Published online: 24 October 2015

\section{References}

1. Tavolo Tecnico Operativo Interdisciplinare sulla Promozione dell'Allattamento al Seno (TAS). Allattamento al seno nelle Strutture Sanitarie in Italia. Report sulla Survey Nazionale 2014. Revisione del maggio 2015. Ministero della Salute. http://www.salute.gov.it/imgs/C_17_pubblicazioni_2256_allegato.pdf

2. Giovannini M, Banderali G, Radaelli G, Carmine V, Riva E, Agostoni C. Monitoring breastfeeding rates in Italy: national surveys 1995 and 1999. Acta Paediatr. 2003;92:357-63.

3. Davanzo R, De Cunto A. Breastfeeding promotion and neonatological practices. Early Hum Dev. 2013;8954:S20-2.

4. Istat. Anno 2013. Gravidanza, parto e allattamento. 2014

5. WHO/UNICEF. Global strategy for infant and Young Child feeding. Geneva: WHO; 2003.

6. Section on Breastfeeding. Breastfeeding and the use of human milk. Pediatrics. 2012;129(3):e827-41. Epub 2012 Feb 27.

7. Davanzo R. Allattamento al seno e personale sanitario: la formazione è efficace? Medico Bambino. 2002;21:443-7.

8. Szucs KA, Miracle DJ, Rosenman MB. Breastfeeding knowledge, attitudes and practices among providers in a medical home. Breastfeed Med. 2009;4:31-42.

9. Davanzo R, Bua J, De Cunto A, Farina ML, De Ponti F, Clavenna A, Mandrella S, Sagone A, Clementi M. Advising Mothers on the Use of Medications during Breastfeeding: A Need for a Positive Attitude. J Hum Lact. 2015. [Epub ahead of print]

10. Bartick MC, Stuebe AM, Schwarz EB, Luongo C, Reinhold AG, Foster EM. Cost analysis of maternal disease associated with suboptimal breastfeeding. Obstet Gynecol. 2013;122(1):111-9. doi:10.1097/AOG.0b013e318297a047. 
11. Bartick M, Reinhold A. The burden of suboptimal breastfeeding in the United States: a pediatric cost analysis. Pediatrics. 2010;125(5):e1048-56. doi:10.1542/ peds.2009-1616. Epub 2010 Apr 5.

12. Cattaneo A, Ronfani L, Burmaz T, Quintero-Romero S, Macaluso A, Di Mario S. Infant feeding and cost of health care: a cohort study. Acta Paediatr. 2006;95(5):540-6.

13. Pokhrel S, Quigley MA, Fox-Rushby J, McCormick F, Williams A, Trueman P, et al. Potential economic impacts from improving breastfeeding rates in the UK. Arch Dis Child. 2015;100(4):334-40. doi:10.1136/archdischild-2014-306701. Epub 2014 Dec 4.

14. Davanzo R, Ronfani L, Brovedani P, Demarini S. Breastfeeding in Neonatal Intensive Care Unit Study Group. Breast feeding very-low-birthweight infants at discharge: a multicentre study using WHO definitions. Paediatr Perinat Epidemiol. 2009;23(6):591-6. doi:10.1111/j.1365-3016.2009.01068.x.

15. WHO/UNICEF. Acceptable medical reasons for use of breast-milk substitutes. WHO/NMH/NHD/09.01, WHO/FCH/CAH/09.01, Geneva, 2009

16. Cova MA, Stacul F, Quaranta R, Guastalla P, Salvatori G, Banderali G, et al. Radiological contrast media in the breastfeeding woman: a position paper of the Italian Society of Radiology (SIRM), the Italian Society of Paediatrics (SIP), the Italian Society of Neonatology (SIN) and the Task Force on Breastfeeding, Ministry of Health, Italy. Eur Radiol. 2014;24(8):2012-22. doi:10.1007/s00330-014-3198-6.

17. Cetin I, Assandro P, Massari M, Sagone A, Gennaretti R, Donzelli G, et al. Working Group On Breastfeeding, Italian Society Of Perinatal Medicine And Task Force On Breastfeeding, Ministry Of Health, Italy. Breastfeeding during Pregnancy: Position Paper of the Italian Society of Perinatal Medicine and the Task Force on Breastfeeding, Ministry of Health, Italy. J Hum Lact. 2014;30:20-2.

18. Chung M, Raman G, Trikalinos T, Lau J, Ip S. Interventions in primary care to promote breastfeeding: an evidence review for the U.S. Preventive Services Task Force. Ann Intern Med. 2008;149(8):565-82.

19. Cleminson J, Oddie S, Renfrew MJ, McGuire W. Being baby friendly: evidence-based breastfeeding support. Arch Dis Child Fetal Neonat Ed. 2015;100:F173-8.

20. Lebwohl B, Murray JA, Verdú EF, Crowe SE, Dennis M, Fasano A, et al. Gluten Introduction, Breastfeeding, and Celiac Disease: Back to the Drawing Board. Am J Gastroenterol. 2015 on line first

21. Lodge CJ, Tan DJ, Lau M, Dai X, Tham R, Lowe AJ, et al. Breastfeeding and asthma and allergies: a systematic review and meta-analysis. Acta Paediatr. 2015. doi:10.1111/apa.13132. [Epub ahead of print]

22. Critch JN, Canadian Paediatric Society, Nutrition and Gastroenterology Committee. Nutrition for healthy term infants, six to 24 months: An overview. Paediatr Child Health. 2014;19(10):547-52. English, French.

23. Belfort MB, Rifas-Shiman SL, Kleinman KP, Guthrie LB, Bellinger DC, Taveras EM, Gillman MW, Oken E. Breastfeeding and educational achievement at age 5. JAMA Pediatr. 2013 Jul 29. doi:10.1001/jamapediatrics.2013.455. [Epub ahead of print] Infant

24. Walfisch A, Sermer C, Cressman A, Koren G, Heikkilä K, Kelly Y, et al. Breast milk and cognitive development-the role of confounders: a systematic review. BMJ Open. 2013;3(8):e003259. doi:10.1136/bmjopen-2013-003259.

25. Sacker A, Kelly Y, lacovou M, Cable N, Bartley M. Breast feeding and intergenerational social mobility: what are the mechanisms? Arch Dis Child. 2013;98(9):666-71. doi:10.1136/archdischild-2012-303199. Epub 2013 Jun 24.

26. Nyaradi A, Oddy WH, Hickling S, Li J, Foster JK. The relationship between nutrition in infancy and cognitive performance during adolescence. Front Nutr. 2015;2:2. doi:10.3389/fnut.2015.00002. eCollection 2015.

27. Renfrew MJ, Craig D, Dyson L, McCormick F, Rice S, King SE, et al. Breastfeeding promotion for infants in neonatal units: a systematic review and economic analysis. Health Technol Assess. 2009;13(40):1-146. iii-iv.

28. Italian Association of Human Milk Banks, Arslanoglu S, Bertino E, Tonetto P, De Nisi G, Ambruzzi AM, et al. Guidelines for the establishment and operation of a donor human milk bank. J Matern Fetal Neonatal Med. 2010;23 Suppl 2:1-20.

29. Arslanoglu S, Moro GE, Bellù R, Turoli D, De Nisi G, Tonetto $P$, et al. Presence of human milk bank is associated with elevated rate of exclusive breastfeeding in VLBW infants. J Perinat Med. 2012;15:1-3.

\section{Submit your next manuscript to BioMed Central and take full advantage of:}

- Convenient online submission

- Thorough peer review

- No space constraints or color figure charges

- Immediate publication on acceptance

- Inclusion in PubMed, CAS, Scopus and Google Scholar

- Research which is freely available for redistribution 